\title{
From cognitive capability to social reform? Shifting perceptions of learning in immersive virtual worlds
}

\author{
Maggi Savin-Baden* \\ Coventry University, Coventry, $U K$
}

(Received 3 April 2008; final version received 8 September 2008)

\begin{abstract}
Learning in immersive virtual worlds (simulations and virtual worlds such as Second Life) could become a central learning approach in many curricula, but the socio-political impact of virtual world learning on higher education remains under-researched. Much of the recent research into learning in immersive virtual worlds centres around games and gaming and is largely underpinned by cognitive learning theories that focus on linearity, problem-solving and the importance of attaining the 'right answer' or game plan. Most research to date has been undertaken into students' experiences of virtual learning environments, discussion forums and perspectives about what and how online learning has been implemented. This article reviews the literature relating to learning in immersive virtual worlds, and suggests that there needs to be a reconsideration of what 'learning' means in such spaces.
\end{abstract}

Keywords: immersive virtual worlds; literature review; learning

\section{Introduction}

This article seeks to explore the ways in which learning theories and current literature might inform the use of immersive virtual worlds ${ }^{1}$ and argues for a move towards a social reform perspective that is more appropriate not only for an increasingly diverse student population, across the higher education sector, but also in terms of the changing nature of the university. For example, students of the twenty-first century, compared with former years, are more mixed in age range, tend to be in employment whilst studying, learn on the move and have diverse expectations of what learning should be. It will be argued throughout that:

(1) Implementation of learning in immersive virtual worlds in higher education lacks pedagogical underpinning;

(2) E-learning and learning in immersive virtual worlds have, to date, largely been informed by cognitive approaches to learning; and

(3) 'Learning' in immersive worlds, in the context of higher education, needs to be reconsidered in the context of a social reform model of education.

\section{The impact of cognitive theories on immersive virtual worlds research}

Much of the recent research into learning in immersive worlds centres around games and gaming and is largely underpinned by cognitive learning theories that focus on linearity,

\footnotetext{
*Email: hsx249@coventry.ac.uk
} 
problem-solving and the importance of attaining the 'right answer' or game plan. For example, Ravenscroft and Matheson (2002) discuss using dialogue games with 15-16-year-olds which comprise ways of computing dialogic interaction between tutor and students that can be measured to ensure the students get the right answers in disciplines such as physics. A study by Johnson (2007) explored how students perceived knowledge construction in the context of an e-learning environment, and argued that the synchronous discussion resulted in learning that was deep and reflexive, yet there was little evidence to support this. However, other researchers have argued that they are using immersive virtual worlds to enable students to transfer skills from one area to another, for example:

The River City MUVE is centered on skills of hypothesis formation and experimental design, as well as on content related to national standards and assessments in biology and ecology ... Students learn to behave as scientists while they collaboratively identify problems through observation and inference, form and test hypotheses, and deduce evidence-based conclusions about underlying causes. (Dede 2005)

Yet one of the underlying principles of this approach is the assumption that transfer across domains is relatively straightforward. Eva, Neville and Norman (1998) have suggested that the problem-solving theories concerning ways in which students transfer knowledge from one context to another fall into two broad areas:

- Abstract induction, which presumes that students learn principles or concepts from exposure to multiple problems by abstracting a general rule, thus it is independent of context.

- Conservative induction, which assumes that the rule is not separated from the problem context but that expertise emerges from having the same principle available in multiple problem contexts.

The subtextual assumption here is that by teaching principles of problems, students will then use these principles to solve other similar problems. Inevitably, this raises questions about the extent to which problem-solving can be classed as a generalisable skill and whether some knowledge is necessarily foundational to other knowledge or indeed transferable from one context to another. Such a difficulty can also be seen in the literature relating to affordances. The concept of affordances has become increasingly used in research and technology since the late 1980s. The term originated from Gibson, who developed the ecological approach to visual perception in which he argued that:

When no constraints are put in the visuals system, we look around, walk up to something interesting and move around it so as to see it from all sides, and go from one vista to another. That is natural vision ... (Gibson 1979, 1)

Thus is it possible to see how this term has been (mis-)appropriated when we realise that he argued: "The affordances of the environment are what it offers, the animal, what it provides or furnishes, for good or ill" (115, original italics). The use then of 'affordances' seems at one level to have provoked an overemphasis on what particular technologies prompt or allow us to do, bringing with it a sense of covert control. Indeed Malaby (2006) suggested that virtual worlds "present for their users an increasingly varied and complex set of affordances" (144). On the other hand there is a sense that the term is used because it offers a linguistic position and format through which it is possible to discuss the complexity, interactions and impact of technologies on higher education. Thus, as Oliver $(2005,412)$ 
argues, the notion of affordances has little value unless "we are willing to abandon constructivist values in order to explore 'inherent properties' in a positivistic sense". One option here that might help to counter Oliver's concerns would be to adopt actor-network theory (ANT). This approach (Latour 2005) seeks to explain the interaction between the material and the semiotic, but carries with it a sense of precariousness, since the focus is on nodes that have as many dimensions as connections with the strength of the approach occurring through dissemination. Such a stance allows for technology to be seen as an iterative component of the technology-pedagogy narrative, rather than something that is reductionist. However, what remains problematic with ANT is that the approach does not allow for explanation to be made about why particular networks take the forms they do, which may in fact underline further Oliver's concerns about affordances.

Within the current literature there are also other areas and terms which compound the difficulty of discussing learning in immersive virtual worlds. For example, the term 'virtual learning environment' (VLE) is generally defined as a set of learning and teaching tools involving online technology designed to enhance students' learning experience, for example, Blackboard, WebCT, but because of the words 'virtual' and 'environment' they have been confused with immersive virtual worlds, which are in fact very different. There are also phrases such as Web 1.0 and Web 2.0 which, whilst helpful in defining differences in many instances, are also not unproblematic. For example, Web 1.0 was largely seen as the movement of information into digital spaces, for example news, music and information, and is in many ways epitomised by the VLE as an information-giving platform with some other features such as discussion fora. Web 2.0 on the other hand is characterised by social learning and networking and the use of web services to integrate diverse sources of data.

Since the emergence of the Web 2.0 movement in 2004, there has been considerable debate about what constitutes Web 2.0 and what does not. Yet it would seem that the growth of this movement is liquid in nature and is something that is constantly developing and emerging differently. O'Reilly (2005) has argued that it “doesn't have a hard boundary, but rather a gravitational core". Others suggest that it does not refer to one development, but rather a series of emergent technologies such as Google, flickr, del.icio.us, wikis and blogs. Further, authors such as Hargittai $(2002,2007)$ have found through surveys of young adults that the use of sites such as Facebook, MySpace, Xanga, and Friendster is not randomly distributed across a group of highly wired users. Although gender, race and ethnicity, and parental educational background are associated with use, people with more experience and autonomy of use are more likely to be users of such sites. However, as Alexander argues, "Ultimately, the label 'Web 2.0' is far less important than the concepts, projects and practices included in its scope" (2006, 33). A further difficulty of the Web 2.0 movement seems to be some rather naive assumptions and impositions that appear to prevent engagement with complex issues from a critical perspective. For example, there are those (such as Bruns and Humphreys 2005) that believe that current education systems are still text-based and linear, arguing instead that wikis are not. Such views illustrate a naive stance toward wikis, which can be linear and may change relatively little over a year. Yet such perspectives illustrate that there are many in the digital community who lack in-depth understandings of models of knowledge and diverse approaches to teaching, learning and assessment.

Yet what is interesting about the studies and literature that relate to learning in immersive virtual worlds is the tendency to focus on cognitive mapping and the organisation of learning. One of the earliest cognitive theories, bridging the gap from behaviourism to constructivism, came through Tolman's work on sign theory and cognitive mapping. Tolman (1948) believed that learners have goals and follow signs on the way to the goal. Thus learners should try to find the overall structure of the problem and then the gaps and 
incongruities become the stimuli for learning. In practice this means that instruction should be based on the organisation of learning (Wertheimer 1923/1938, 1959). More recently Ausubel, Novak, and Hanesian's assimilation theory of learning (1978) suggested that learning occurs when a learner is presented with new information whose external or internal characteristics enables the learner to associate it with previous learning. Thus advanced organisers, or a bridge between new material and existing ideas, are instrumental for learning. Therefore in terms of learning in immersive worlds, prior experience of gaming may, for some students, be advanced organisers. However, the cognitive developmental theorists offer models that take account of cognition and development and are perhaps more helpful models when considering learning in immersive worlds. The teacher's concern here is in enabling students to develop both understandings of the nature of knowledge and ways of handling different conceptions of the world, so that knowledge acquisition is seen as an active process. What has emerged from combining cognitive and developmental fields has been the extension of Piaget's (Piaget, 1929) work by Perry, who undertook a qualitative study of men at Harvard. He devised nine positions that described how male students' conceptions of the nature and origins of knowledge evolved (Perry 1970, 1988). This study put issues of learner experience centre stage and suggested that students proceed through a sequence of developmental stages. Belenky et al. (1986), stimulated by Perry's work, explored diverse women's perspectives and identified five categories of 'ways of knowing'. For example, women began from a position of silence where they saw themselves as mindless and in later stages both constructed and created knowledge. Such models acknowledge that what is missing from many curricula is recognition of the role and relevance of learning from and through experience, which can prompt the shaping and reconstructing of people's lives as learners and teachers. Yet before using these as informing theories for future research possibilities, it is useful to explore the research and literature that has been undertaken to date.

\section{Informing literature}

There has been a series of studies funded by the Joint Information Systems Committee (JISC) in the UK that have explored students' perspectives of e-learning. Firstly, Sharpe et al. (2005) undertook a scoping study that provided a database of research, but found few studies whose main focus was students' experiences. Secondly, the LEX study (Creanor et al. 2006) undertook a snapshot of learner experience and found students did not see e-learning as separate from other approaches and that control and choice over technologies were important to them. Thirdly, the LXP study (Conole et al. 2006) was perhaps the most extensive study and used mixed methods to examine disciplinary differences in technology use by university students. This study found that students often use personal technology such as mobile phones and standard software for learning, that search engines were preferred to libraries and that peers provided invisible support and "an underworld of communication" (11). These studies, although using relatively small data sets, would seem to indicate students' experiences of e-learning are more complex and wideranging than many university tutors realise. Such studies would also seem to indicate that linearity, narrow problem-solving and bounded approaches to learning where knowledge is managed and patrolled by staff is likely to be inappropriate for learning at university in the twenty-first century.

The most recent literature review that would seem to offer some purchase on students' experiences is that undertaken by de Freitas (2006). This review examined the various uses of game-based learning worldwide. It presents a comprehensive overview of a diverse 
number of games, simulations and immersive worlds. Yet although this review is entitled 'Learning in Immersive Worlds', there is relatively little about learning per se, illustrating that documenting educational practice is not the same as engaging with the nature of learning. What de Freitas does in fact offer is an overview of what is occurring in gaming worlds which are exploited for education, but there is minimal exploration of the pedagogical impact and no location of this literature in relation to the student experience. It is an interesting review but it offers little in the way of either the pedagogical positioning of games or recommendations for locating them pedagogically in the curriculum.

The most extensive research to date undertaken into students' experiences of VLEs includes explorations of discussion forums and perspectives about what and how online learning has been implemented. This literature indicates largely that technology has led the pedagogy, but Sharpe et al. (2006) have pointed out that successful institutions' rationales for implementing e-learning have included flexibility of provision, supporting diversity, enhancing the campus experience, operating in a global context and efficiency. Yet none of these recommendations are pedagogically located. Furthermore, there is little, if any, exploration of the kinds of e-learning spaces that are commonly adopted or the rationale for their use. For example, VLEs such as Blackboard may be used in ways that contain and control learning, whereas there is a current tendency to use IVWs for the kinds of learning that focus on the deconstruction of knowledges and identity work. Although this is a generalisation, it does seem to be a trend. However, the point is that how, when and why particular e-spaces are used does bear further exploration. This is because the type of espace and the way in which it is used (or not used) to manage knowledge will affect the kinds of learning opportunities offered to students. However, there are a number of studies that have specifically focused on the students' experience. Jones and Cooke (2006) used two case studies to explore students' online discussions to enhance understanding of how students learn. Students were positive overall about their online experience, even if they did encounter problems, such as fellow students not participating in discussion forums. Bayne (2005) studied how students and teachers experienced their identities online, and how these related to their embodied 'real life' identities. A common perspective amongst students emerged in which online modes of identity formation were viewed negatively, primarily as the true self being deceitfully threatened by the online being. Bayne's research concluded that tutors' use of the online space to (re)construct themselves as authority figures was far less problematic and far less a cause of anxiety than the identity narratives provided by students.

The rationale for using learning in IVWs in higher education, it is suggested here, is because practicing skills within a virtual environment online offers advantages over learning through real-life practice, in particular the exposure of learners to a wide range of scenarios (more than they are likely to meet in a standard face-to-face programme) at a time and pace convenient to the learner, together with consistent feedback. It offers learners the chance to make mistakes without real-world repercussions. Further, with the increasing use of distance programmes, IVWs create online learning opportunities which are sufficiently immersive and collaborative outside the tutorial room, in ways that current VLE systems do not. Learning in IVWs seems to offer new opportunities to the study of the socio-political impact of learning in higher education. This is because spaces such as Second Life are universal, are not bounded by time or geography and in particular adopt different learning values than other learning spaces (Savin-Baden 2007; Olsen et al. 2004; Malaby 2006). It would seem then that there remains little research into or understanding of student learning in IVWs and perhaps adopting a social reform perspective could inform such learning in advance of implementations which would otherwise take a narrowly 
focused cognitive stance. It may be that it is possible to locate approaches to e-learning as shown in Table 1, in order to illustrate the possible challenges of utilising immersive virtual worlds for learning.

\section{Social reform for learning in immersive worlds: structuration in action?}

Although cognitive theories can be seen as being located along a trajectory between those who stratify and order thinking and knowledge, and those who see cognition as a developmental process, a shift is required towards a social reform model in the context of learning in immersive worlds. This is because, to date, much of the learning in higher education tends to ignore this approach, despite it seeming to be a sound fit with both Web 2.0 learning and particularly learning in immersive virtual worlds. This approach focuses on teaching as a collective process which challenges the status quo (and would seem to reach beyond earlier approaches suggested by Freire 1974 and Mezirow 1981). Thus learning is seen as a process of encouraging students to consider how they are positioned through the discourses and practices with which they are expected to engage. In practice, a shift to this approach in learning in immersive virtual worlds would mean:

Class discussion is focused less on how knowledge has been created, and more by whom and for what purposes. Texts are interrogated for what is said and what is not said; what is included and what is excluded; who is represented and who is omitted from the dominant discourse. Students are encouraged to take critical stances to give them power to take social action to improve their own lives and the lives of others. (Pratt and Collins 2006)

This approach then is not only about learning with technology but deconstructing how given notions of technology and pedagogy position students. A shift towards a social reform perspective will require that learning in immersive virtual worlds will need to focus extensively on the relationship between structure and agency. Human agency addresses the way in which people's aspirations, expectations and perceptions influence the way that they execute their roles. By responding to human agency at an individual level, universities will be imbued with a degree of flexibility that will enable adaptation to the needs of the varied and diverse student communities involved. This will then lead to the understanding that individual empowerment is a vector for knowledge transfer; the system itself is only a mechanism which provides merely a facilitating framework. What is particularly important here is the structure-agency debate that introduces questions about the nature of social behaviour: whether it is ultimately predictable in terms of the creative volition of the individual, or is largely a product of socialisation, interaction and greater social structures. Giddens' theory of structuration (Giddens 1984) is an attempt to reconcile theoretical dichotomies such as structure and agency. Giddens suggests human agency and social structure are in a relationship with each other, and it is the repetition of the acts of individual agents which reproduces the structure. Structures can be modified by human agents who are also constrained by those structures, which illustrates the complex interplay of the mutually constitutive duality of structure and agency. However, in light of shifts in time and spaces and the intersections of identities, it might be that social structure such as traditions, institutions, moral codes and established ways of doing things can be changed when students begin to ignore them, replace them or reproduce them differently. Thus perhaps what needs to be explored further in terms of student experiences of learning in immersive virtual worlds is a regeneration of the three types of structures (Giddens 1984) in social systems, which are perhaps more reflective of Giddens' more recent work on identity and society, which I have reconstituted as follows: 


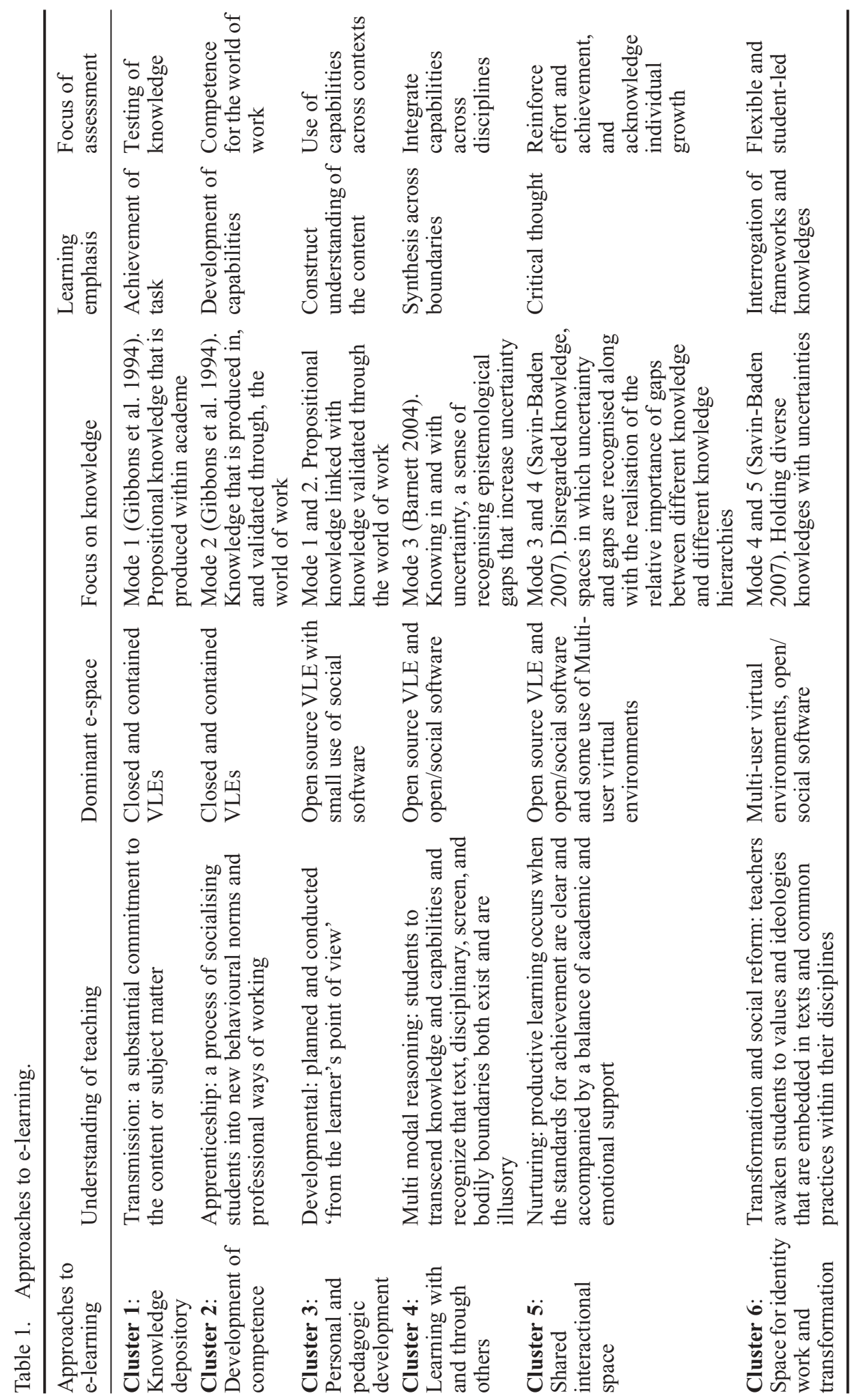


- Signification: produces meaning through organised webs of language and even the language of webs

- Legitimation: produces a moral order via naturalisation in societal norms, values and standards, but which is challenged through knowledges created in and through immersive worlds

- Domination: produces (and is an exercise of) power, originating from the control of resources, which can be transgressed though produsage. ${ }^{2}$

What is perhaps needed are 'smooth curricula spaces' (Savin-Baden 2007, following Deleuze and Guattari 1988 and Bayne 2004) which are open, flexible and contested; spaces in which both learning and learners are always on the move. Movement in such curricula is not towards a given trajectory. Instead, there is a sense of displacement of notions of time and place, so that curricula are delineated with and through the staff and students; they are defined by the creators of the space(s). These kinds of curricula are likely to be seen as risky since they prompt consideration of what counts as legitimate knowledge. In these kinds of curricula students will be encouraged to examine the underlying structures and belief systems implicit within what is being learned, in order to not only understand the disciplinary area but also its credence. What will be important in the creation of these kinds of curricula is the position of disregarded knowledge ${ }^{3}$ as a central space, in which uncertainty and gaps are recognised along with the realisation of the relative importance of gaps between different knowledges and different knowledge hierarchies. The increasing need to manage the interplay of identities in face-to-face lives is further complicated by managing the embodied identities of the virtual world. For example, working and learning in immersive virtual worlds introduces juxtaposition and cross-over between real life and Second Life, where multiple pasts travel with us. This would seem to suggest that a trajectory into/in/with Web 2.0 technologies requires a university that engages more thoroughly with these 'third spaces'. 4 Such a university would enable an exploration of the ways in which past, current and future identities are present, embodied and multiply interacting with each other in these spaces. Further, there are issues about learning, play and fun and how we also play in and through our identities in virtual spaces. Rieber, Smith, and Noah (1998) have suggested that the notion of 'serious play', which is characterised as an intense learning experience, involves considerable energy and commitment and that serious play is important for the development of high order thinking, commitment and engagement. Immersive world identities are ones that would seem to be at play in this way; it is a demanding and engaging environment, whether travelling, exploring, or participating in seminars. Universities of the future will need to develop spaces in worlds such as this, but also utilise games and play effectively - whether through game playing or games design. An example of this is seen in the Quest Atlantis project (Barab, Arici, and Jackson 2005), a 3D game for children that would essentially seem to have a problem-based learning pedagogy as its central focus. Approaches such as this, which mirror problem-based learning for critical contestability (Savin-Baden 2000), need to be adopted in higher education in order to create spaces for curricula and societal spaces of social reform. If we are to create such immersive learning spaces where learning is liquid and knowledge is on the move, then curricula cannot be formulated in advance, as McWilliam has argued: "From fixed and immutable, curriculum need [sic] to be conceptualised as content for meddling with" (2005, 7, original emphasis). Yet curricula need to be seen not just as content for meddling with, but as diverse spaces of opportunity. It is in such spaces that we can explore the possibilities for creating curricula for living with chronic uncertainty, liminality and spaces of unknowability. Curricula then will become a series of open-ended spaces rather than a series of permissions to proceed that 
focus on compliance and rule-based models. Such open-ended curricula will be provisional, unstable and uncertain, and will reflect the translocational state of the university of the future.

\section{In conclusion}

For students who spend over six hours a day on social networking and just over three hours a day on email, surfing the net and instant messaging (Harris Interactive 2006), it is clear universities need to rethink learning in immersive worlds. Indeed, universities need to begin to consider ways in which they might unbracket online and offline learning, as Evans has suggested (2004). Immersive virtual worlds offer different textualities that are increasingly ushering in new issues and concerns, such as consensus over authority and process over product. Indeed, what also seems to be emerging from immersive virtual worlds is not just different textualities, but the spatialisation of knowledge, whereby knowledge is multiply located and linked, reconstituted and contested across time and space. In immersive virtual worlds temporality and spatiality become not just contested but dynamic and intersected by one another. Maybe what is needed is the creation not of universities but ruins, to create borderless spaces, much as the University of Bologna once was. Perhaps this is what social reform approaches offer over cognitive approaches to learning capabilities: the opportunity to strip universities of their architectured and disciplinary walls and to interrupt established practices and the power inherent in those practices.

\section{Acknowledgement}

With thanks to Dr Hamish McLeod, University of Edinburgh for his feedback on this article in its initial configuration

\section{Notes}

1. Immersive virtual worlds are defined here as $3 \mathrm{D}$ virtual worlds that can be/are adapted for educational purposes.

2. Bruns (2007) has suggested that we are now in the realms of 'produsage', characterised by community-based production, fluid roles, unfinished artefacts and common property.

3. Disregarded knowledge (Savin-Baden 2007) encompasses knowledge often equated with emotional intelligence, such as when and how to use self-promotion, when to keep silent and when to intervene, but also with Haraway's (1991) concept of responsible knowledge - the need to take responsibility for the position from which we speak.

4. The notion of the 'third space' captures the idea that there are "particular discursive spaces ... in which alternative and competing discourses and positioning transform conflict and difference into rich zones of collaboration and learning" (Gutiérrez, Baquedano-Lopez, and Tejeda 1999, 286-7).

\section{References}

Alexander, B. 2006. Web 2.0: A new wave of innovation for teaching and learning? Educause Review 41, no. 2. http://www.educause.edu/apps/er/erm06/erm0621.asp.

Ausubel, D.P., J.S. Novak, and H. Hanesian. 1978. Educational psychology: A cognitive view. New York: Holt, Rinehart and Winston.

Barab, S.A., A. Arici, and C. Jackson. 2005. Eat your vegetables and do your homework: A designbased investigation of enjoyment and meaning in learning. Educational Technology 65, no. 1: $15-21$.

Barnett, R. 2004. Learning for an unknown future. Higher Education Research and Development 23, no. 3: 247-60. 
Bayne, S. 2004. Smoothness and striation in digital learning spaces. E-Learning Journal 1, no. 2: $302-16$.

- 2005. Deceit, desire and control: The identities of learners and teachers in cyberspace. In Education in cyberspace, ed. R. Land and S. Bayne, 26-42. London: Routledge.

Belenky, M.F., B.M. Clinchy, N.R. Goldberger, and J.M. Tarule. 1986. Women's ways of knowing. New York: Basic Books Inc.

Bruns, A. 2007. Beyond difference: Reconfiguring education for the user-led age. Paper presented at Ideas in Cyberspace Education, March 21-23, at 3 Ross Priory, Loch Lomond. www.education. ed.ac.uk/ice3/papers/bruns.html.

Bruns, A., and S. Humphreys. 2005. Wikis in and assessment: The M $>$ cyclopedia project. In Proceedings of WikiSym 2005. http://snurb.info/files/Wikis\%20in\%20Teaching\%20and\%20 Assessment.pdf.

Conole, G., M. de Laat, T. Dillon, and T. Darby. 2006. JISC LXP Student experiences of technologies - final report. JISC report, November 2006.

Creanor, L., K. Trinder, D. Gowan, and C. Howells. 2006. LEX. The learner experience of e-learning final report. http://www.jisc.ac.uk/uploaded_documents/LEX\%20Final\%20 Report_August06.pdf.

de Freitas, S. 2006. Learning in Immersive Worlds: A review of game based learning. http:// www.jisc.ac.uk/eli_outcomes.html.

Dede, C. 2005. Planning for neomillennial learning styles: Implications for investments in technology and faculty. In Educating the Net generation, ed. D.G. Oblinger and J.L. Oblinger. http:// www.educause.edu/EducatingtheNetGeneration/5989.

Deleuze, G., and F. Guattari. 1988. A thousand plateaus: Capitalism and schizophrenia. London: Continuum.

Eva, K.W., A.J. Neville, and G.R. Norman. 1998. Exploring the etiology and content specificity: Factors influencing analogic transfer and problem solving. Academic Medicine 73, no. 10: S1-5.

Evans, F. 2004. Cyberspace and the concept of democracy. Studies in Practical Philosophy: A Journal of Ethical and Political Philosophy 4, no. 1: 71-101.

Freire, P. 1974. Education: The practice of freedom. London: Writers and Readers Co-operative.

Gibbons, M., C. Limoges, H. Nowotny, S. Schwarzman, P. Scott, and M. Trow. 1994. The new production of knowledge: The dynamics of science and research in contemporary societies. London: Sage.

Gibson, J. 1979. The ecological approach to visual perception. Boston: Houghton Mifflin.

Giddens, A. 1984. The constitution of society. Outline of the theory of structuration. Cambridge: Polity Press.

Gutiérrez, K., P. Baquedano-Lopez, and C. Tejeda. 1999. Rethinking diversity: Hybridity and hybrid language practices in the third space. Mind, Culture, and Activity: An International Journal 6, no. 4: 286-303.

Haraway, D. 1991. Simians, cyborgs, and women: The reinvention of nature. London: Routledge.

Hargittai, E. 2002. Second-level digital divide: Differences in people's online skills. First Monday 7, no. 4. http://www.firstmonday.org/issues/issue7_4/hargittai/.

- 2007. A framework for studying differences in people's digital media uses. In Cyberworld unlimited?, ed. N. Kutscher and. H. Otto, 121-37. Wiesbaden: VS Verlag für Sozialwissenschaften/GWV Fachverlage GmbH.

Harris Interactive. 2006. College students surf back to campus on a wave of digital connections. http://www.harrisinteractive.com/news/newsletters/clientnews/2006_alloy2.pdf.

Johnson, H. 2007. Dialogue and the construction of knowledge in e-Learning: Exploring students' perceptions of their learning while using Blackboard's asynchronous discussion board. European Journal of Open, Distance and E-Learning. http://www.eurodl.org/materials/briefs/ 2007/Henry_Johnson_GBA.htm.

Jones, R.E., and L. Cooke. 2006. A window into learning: Case studies of online group communication and collaboration. ALT-J, Research in Learning Technology 14, no. 3: 261-74.

Latour, B. 2005. Reassembling the social. Oxford: Oxford University Press.

Malaby, T. 2006. Parlaying value: Capital in and beyond virtual worlds. Games and Culture 1, no. 2: $141-62$.

McWilliam, E. 2005. Unlearning pedagogy. Journal of Learning Design 1, no. 1: 1-11. http:// www.jld.qut.edu.au/publications/vollno1/. 
Mezirow, J. 1981. A critical theory of adult learning and education. Adult Education 32: 3-24.

Oliver, M. 2005. The problem with affordance. E-Learning 2, no. 4: 402-13.

Olsen, S.F., S.S. Jensen, K. Bolander, F. Deepwell, C. Jones, and S. Mann. 2004. Narratives from the 3D Agora-world. Proceedings of the networked learning conference, 2004, University of Lancaster. http://www.networkedlearningconference.org.uk/past/nlc2004/proceedings/individual _papers/olsen_et_al.htm

O'Reilly, T. 2005. What is Web 2.0?: Design patterns and business models for the next generation of software. http://www.oreillynet.com/pub/a/oreilly/tim/news/2005/09/30/what-is-web-20.html? page $=1$.

Perry, W.G. 1970. Forms of intellectual and ethical development during the college years: A scheme. New York: Holt, Rinehart and Winston.

. 1988. Different worlds in the same classroom. In Improving learning. New perspectives, ed. P. Ramsden, 145-61. London: Kogan Page.

Piaget, J. 1929. The child's conception of the world. London: Routledge and Kegan Paul.

Pratt, D.D., and J. Collins. 2006. Five perspectives on teaching. Paper presented at the International Problem-based Learning Symposium 2007, Re-inventing Problem-based Learning, at the Republic Polytechnic, Singapore. www.rp.sg/symposium/download/Summary\%20 Paragraphs.pdf.

Ravenscroft, A., and M.P. Matheson. 2002. Developing and evaluating dialogue games for collaborative e-learning. Journal of Computer Assisted Learning 18: 93-101.

Rieber, L.P., L. Smith, and D. Noah. 1998. The value of serious play. Educational Technology 38, no. 6: 29-37.

Savin-Baden, M. 2000. Problem-based learning in higher education: Untold stories. Buckingham, UK: Open University Press/SRHE.

. 2007. Learning spaces. Maidenhead: McGraw Hill /SRHE.

Sharpe, R., G. Benfield, E. Lessner, and E. DeCicco. 2005. Learner scoping study: Final report. www.jisc.ac.uk/index.cfm?name=elp_learneroutcomes.

Sharpe, R., G. Benfield, G. Roberts, and R. Francis. 2006. The undergraduate experience of blended e-learning: A review of UK literature and practice. Higher Education Academy. http:// www.heacademy.ac.uk/5105.htm.

Tolman, E.C. 1948. Cognitive maps in rats and men. Psychological Review 55: 189-208.

Wertheimer, M. 1923/1938. Laws of organization in perceptual forms. In A source book of Gestalt psychology, trans. W. Ellis, 71-88. London: Routledge and Kegan Paul. Originally published as Untersuchungen zur Lehre von der Gestalt II, Psycologische Forschung 4: 301-50. http:// psy.ed.asu.edu/ classics/Wertheimer/Forms/forms.htm.

. 1959. Productive thinking. New York: Harper and Row. 